\title{
ESTUDO DA REAÇÃO DE OXIDAÇÃO PARCIAL DE ETANOL EM CATALISADORES DE PRATA SUPORTADA EM ALUMINA
}

\author{
S. A. VILLALBA MORALES ${ }^{1}$ e G. P. VALENÇA ${ }^{2}$ \\ ${ }^{1,2}$ Universidade Estadual de Campinas, Faculdade de Engenharia Química \\ E-mail para contato: ${ }^{1}$ sergiovm@feq.unicamp.br, ${ }^{2}$ gustavo@ feq.unicamp.br
}

\begin{abstract}
RESUMO - A partir da oxidação parcial do etanol é possível produzir acetaldeído, ácido acético, acetato de etila, acetona, etc., dependendo das propriedades físicas e químicas do catalisador e das condições de reação. $\mathrm{O}$ presente trabalho apresenta a preparação, caracterização e comportamento catalítico de catalisadores $\mathrm{Ag} / \mathrm{Al}_{2} \mathrm{O}_{3}$, com teores nominais de prata de 0,5 a $5 \% \mathrm{~m} / \mathrm{m}$, na oxidação parcial de etanol em fase vapor. Os catalisadores foram preparados usando o método de impregnação úmida e foram caracterizados por DRX, MEV/EDS, adsorção de nitrogênio e quimissorção de oxigênio. Os testes catalíticos foram realizados utilizando $25 \mathrm{mg}$ de catalisador, temperaturas de reação de 150 a $220^{\circ} \mathrm{C}$ e razão molar etanol $/ \mathrm{O}_{2}$ igual a 0,6 . Os principais produtos de reação foram o acetaldeído, dietil éter, etileno, dióxido de carbono, metanol, ácido acético e água. Os catalisadores com teores de prata igual ou superior a $2 \% \mathrm{~m} / \mathrm{m}$ mostraram-se ativos para a reação de oxidação parcial do etanol a acetaldeído até os $200^{\circ} \mathrm{C}$.
\end{abstract}

\section{INTRODUÇÃO}

As reações de oxidação parcial de álcoois são utilizadas na produção de outros grupos orgânicos como aldeídos, ésteres, ácidos e cetonas, etc., amplamente utilizados como insumos e matérias primas na indústria química. Atualmente, o etanol é o álcool de maior interesse acadêmico e industrial devido a suas aplicações como biocombustível e matéria-prima renovável na produção de compostos intermediários como o etileno, dietil éter, acetaldeído, etc., previamente obtidos mediante diversos processos de refino do petróleo.

A partir da oxidação parcial do etanol em catalisadores suportados é possível produzir substâncias como o hidrogênio (Resta et al., 2008), monóxido de carbono (Hebben et al., 2010), acetaldeído (Murcia et al., 2012) e, inclusive, compostos de maior massa molar como o ácido acético (Tembe et al., 2009) e acetato de etila (Abad et al., 2005), evitando a formação do $\mathrm{CO}_{2}$, o qual é termodinamicamente favorecido mediante a oxidação térmica.

O acetaldeído é o principal produto da oxidação parcial do etanol. Este composto é utilizado na fabricação de alimentos e na produção de substâncias como o ácido acético (Yoneda et al., 2001), 1,3-butadieno (Ho-Jeong et al., 2014), crotonaldeído (Madhavaram et $a l ., 2004)$ e acetato de etila (De lima et al., 2010). A rota de reação para a oxidação do etanol a acetaldeído (Equação 1) é favorecida por catalisadores metálicos do grupo 11 da tabela periódica $(\mathrm{Au}, \mathrm{Ag}$ e $\mathrm{Cu}$ ), sendo as partículas de ouro e cobre os componentes ativos mais 
utilizados para esta reação. Segundo Liu et al. (2008), a fraca adsorção do oxigênio na superfície dos metais do grupo 11 lhes concede características especiais para o desenvolvimento de reações de oxidação parcial de alcoóis e alquenos. Entretanto, outras formulações de catalisadores também têm apresentado atividade catalítica para a oxidação parcial do etanol a acetaldeído, dentre elas se encontram materiais do tipo PdO (Lin et al.,

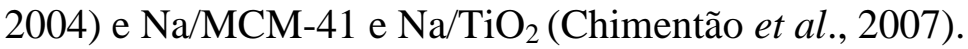

$$
\mathrm{C}_{2} \mathrm{H}_{5} \mathrm{OH}+1 / 2 \mathrm{O}_{2} \rightarrow \mathrm{CH}_{3} \mathrm{CHO}+\mathrm{H}_{2} \mathrm{O}
$$

O mecanismo da conversão do etanol em acetaldeído catalisada por partículas metálicas, com oxigênio atômico adsorvido na sua superfície, foi explicado por Gong et al. (2008) mediante análises de dessorção a temperatura programada (TPD) realizados a catalisadores de $\mathrm{Au}$ (111). Estes autores reportaram que o etanol é inicialmente convertido em etóxido mediante a quebra da ligação $\mathrm{O}-\mathrm{H}$, ocorrendo em seguida a ativação da ligação $\beta-\mathrm{C}-\mathrm{H}$ e produzindo finalmente acetaldeído e água, conforme a Figura 1. A formação de água foi explicada como produto da recombinação entre o grupo hidroxila, formado pela reação entre o hidrogênio (da molécula de etanol) e o oxigênio atômico adsorvido na superfície do ouro, e o hidrogênio acídico extraído posteriormente do etóxido.

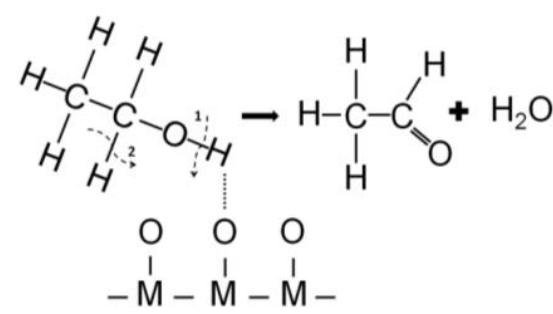

Figura 1 - Oxidação do etanol a acetaldeído em partículas de ouro (M) com oxigênio atômico adsorvido. Adaptado de Gong et al. (2008).

Em comparação a metais como o cobre e ouro, a prata tem mostrado um comportamento catalítico mais seletivo em processos de oxidação parcial tais como a oxidação de etilenoglicol a dioxal (Vodyankina et al., 2000), a conversão do metanol em formaldeído (Qian et al., 2003) e a epoxidação do etileno a óxido de etileno (Van Santen et al., 1986). No entanto, o papel seletivo da prata a produtos da oxidação parcial também é influenciado pelo material de suporte e pelas condições de reação. $\mathrm{Na}$ oxidação do etanol em catalisadores de prata suportada em alumina, reações de desidratação podem ser promovidas como consequência dos sítios ativos presentes no material de suporte, existindo várias rotas reacionais envolvidas. Neste contexto, o presente trabalho teve como principal objetivo estudar o comportamento catalítico de catalisadores $\mathrm{Ag} / \mathrm{Al}_{2} \mathrm{O}_{3}$, com diferentes teores nominais de prata, na reação de oxidação de etanol em fase vapor.

\section{METODOLOGIA EXPERIMENTAL}

\subsection{Preparação dos catalisadores}

A preparação dos catalisadores foi realizada em três etapas. Na primeira etapa foi realizado o pré-tratamento do material de suporte, para o qual a alumina Al3996R (Engelhard) em forma de pellets foi macerada e peneirada para conservar uma granulometria entre $100 \mathrm{e}$ 
200 mesh, equivalente a partículas com tamanhos entre 149 e $74 \mu \mathrm{m}$. A alumina em pó foi seca em estufa durante 12 horas a $110^{\circ} \mathrm{C}$ e calcinada a $500^{\circ} \mathrm{C}$ em ar estático durante 3 horas, com taxa de aquecimento de $10^{\circ} \mathrm{C} \mathrm{min}^{-1}$. Na segunda etapa, a prata foi adicionada ao suporte utilizando o método de impregnação úmida com excesso de solvente. Para isso, soluções aquosas de nitrato de prata (Merck) foram adicionadas a $3 \mathrm{~g}$ da alumina calcinada para obter teores nominais de prata de $0,5,1,2,3$ e $5 \% \mathrm{~m} / \mathrm{m}$. As soluções de nitrato de prata foram adicionadas à alumina a $25^{\circ} \mathrm{C}$ sob agitação. Após 6 horas, a mistura foi aquecida a $80^{\circ} \mathrm{C}$ para remover o excesso de solvente. $\mathrm{O}$ sólido impregnado foi seco em estufa durante $18 \mathrm{~h}$ a $80^{\circ} \mathrm{C}$. $\mathrm{Na}$ terceira etapa, os sólidos secos foram calcinados a $400^{\circ} \mathrm{C}$ por duas horas sob fluxo de $\mathrm{H}_{2} / \mathrm{N}_{2}(5 \% \mathrm{v} / \mathrm{v})$. Após redução, os catalisadores foram esfriados sob fluxo de $\mathrm{N}_{2}$ até temperatura ambiente e passivados com fluxo de $\mathrm{O}_{2} / \mathrm{N}_{2}(5 \% \mathrm{v} / \mathrm{v})$ durante 30 minutos.

\subsection{Caracterização dos catalisadores}

Os catalisadores $\mathrm{Ag} / \mathrm{Al}_{2} \mathrm{O}_{3}$ foram caracterizados pelas técnicas de difração de raios-X (DRX), microscopia eletrônica de varredura acoplada com espectroscopia de energia dispersiva (MEV/EDS), adsorção de nitrogênio e quimissorção de oxigênio. As análises de DRX foram realizadas em um difratômetro Philips X'Pert, com radiação $\mathrm{K} \alpha$ de cobre $\left(\lambda=1.54184 \AA\right.$ ). Os difratogramas foram obtidos para o intervalo $5^{\circ} \leq 2 \Theta \leq 90^{\circ}$, utilizando um passo de $0,05^{\circ}$ e tempo de contagem de 1 segundo por passo. As análises MEV/EDS foram realizadas em num microscópio eletrônico de varredura Leo 440i com Detector de Energia Dispersiva de Raios-X Oxford, modelo 6070. Para a obtenção das micrografias foi utilizada uma tensão de aceleração igual a $15 \mathrm{kV}$ e uma corrente do feixe igual a $50 \mathrm{pA}$. Para a detecção semi-quantitativa da prata a tensão de aceleração e corrente do feixe utilizadas foram de $20 \mathrm{kV}$ e 600 pA. As análises de adsorção de nitrogênio e quimissorção de oxigênio foram realizadas em um equipamento ASAP 2020 (Micromeritics). Para as análises de adsorção de $\mathrm{N}_{2}$ as amostras foram pré-tratadas a vácuo a $350^{\circ} \mathrm{C}$ durante 12 horas. A quimissorção de $\mathrm{O}_{2}$ foi avaliada a $170^{\circ} \mathrm{C}$ em amostras previamente expostas a um fluxo de hidrogênio de $40 \mathrm{ml}$ $\min ^{-1}$ a $400^{\circ} \mathrm{C}$ por 2 horas.

\subsection{Testes catalíticos}

A atividade catalítica dos catalisadores $\mathrm{Ag} / \mathrm{Al}_{2} \mathrm{O}_{3}$ na oxidação do etanol em fase vapor foi avaliada em um sistema de reação utilizando um reator de borosilicato empacotado com $25 \mathrm{mg}$ de catalisador imobilizado com lã de quartzo. Os testes catalíticos foram realizados a temperaturas de reação entre 150 e $220^{\circ} \mathrm{C}$ e razão molar etanol/ $\mathrm{O}_{2}$ igual a 0,6 . Antes da reação os catalisadores foram pré-tratados em fluxo de $\mathrm{H}_{2} / \mathrm{N}_{2}(5 \% \mathrm{v} / \mathrm{v})$ por uma hora. Os reagentes e produtos de reação foram analisados in situ por cromatografia gasosa em um CG 7890 (Agilent Technologies) utilizando detectores de ionização de chama (FID) e condutividade térmica (TCD), configurados em série. A conversão dos reagentes $\left(X_{i}\right)$ e a seletividade dos produtos $\left(S_{i}\right)$ foram calculadas conforme as equações 2 e 3 , respectivamente.

$$
\begin{gathered}
X_{i}(\%)=\frac{n_{i e}-n_{i s}}{n_{i e}} * 100 \\
S_{i}(\%)=\frac{n_{c i}}{n_{c T}} * 100
\end{gathered}
$$


Onde $n_{i e}$ e $n_{i s}$ são as mols de entrada e saída do reagente $i$, e $n_{c i}$ e $n_{c T}$ são as mols de carbono produzidas do componente $i$ e mols de carbono totais dos produtos obtidos.

\section{RESULTADOS E DISCUSSÃO}

\subsection{Propriedades físicas e químicas dos catalisadores $\mathrm{Ag} / \mathrm{Al}_{2} \mathrm{O}_{3}$}

Nos difratogramas de raios-X dos catalisadores $\mathrm{Ag} / \mathrm{Al}_{2} \mathrm{O}_{3}$, apresentados na Figura 2, foram observados unicamente os picos correspondentes à fase gamma da alumina $\left(\gamma-\mathrm{Al}_{2} \mathrm{O}_{3}\right)$, sendo estes os correspondentes aos ângulos de difração $36,6^{\circ}, 39,12^{\circ}, 45,92^{\circ}$ e $66,0^{\circ}$ na escala $2 \theta$ do ângulo de Bragg. Isto pode ser corroborado com o estandar do Joint Committee on Powder Diffraction Standards (JCPDS), ficha catalográfica 10-0425. Este resultado indica que a adição das diversas quantidades de prata ao suporte gamma alumina, assim como as condições utilizadas nas etapas de síntese, não influenciaram nas propriedades estruturais do suporte. A presença das partículas de prata não foi detectada em nenhuma das amostras devido a que a quantidade de metal depositada nos suportes se encontra abaixo do limite de detecção do equipamento.

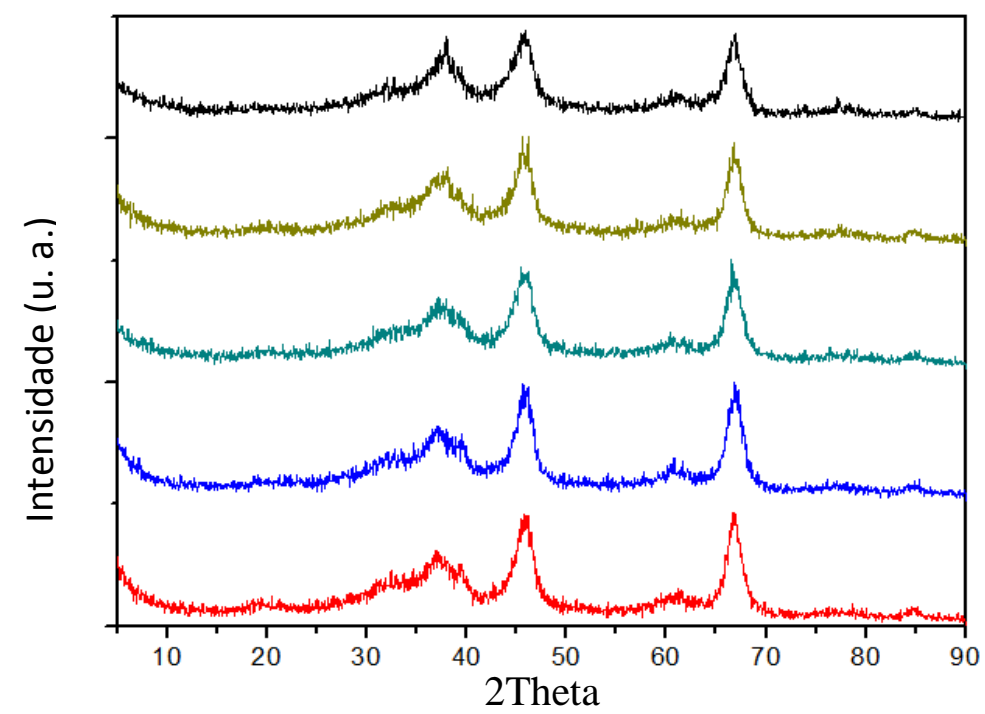

Figura 2 - Difratogramas de raios-X dos catalisadores $0,5 \% \mathrm{Ag} / \mathrm{Al}_{2} \mathrm{O}_{3}(-), 1 \% \mathrm{Ag} / \mathrm{Al}_{2} \mathrm{O}_{3}(-)$, $2 \% \mathrm{Ag} / \mathrm{Al}_{2} \mathrm{O}_{3}(-), 3 \% \mathrm{Ag} / \mathrm{Al}_{2} \mathrm{O}_{3}(-)$ e $5 \% \mathrm{Ag} / \mathrm{Al}_{2} \mathrm{O}_{3}(-)$.

Na Figura 3 são apresentadas micrografias correspondentes ao catalisador preparado com o maior teor de prata (5\%). Nestas micrografias pode ser observada a estrutura amorfa característica das aluminas. 

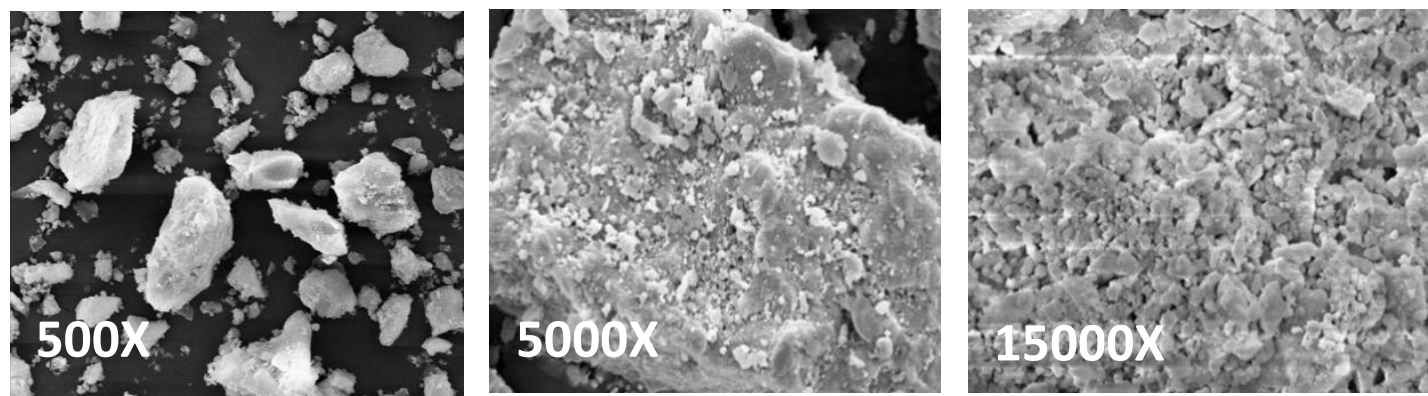

Figura 3 - Micrografias eletrônicas do catalisador $5 \% \mathrm{Ag} / \mathrm{Al}_{2} \mathrm{O}_{3}$.

Os valores de área superficial, diâmetro de partícula metálica e dispersão de metal estimados nas análises de adsorção de $\mathrm{N}_{2}$, quimissorção de $\mathrm{O}_{2}$, assim como a percentagem elementar de prata obtida nas análises EDS são listados na Tabela 1. A área superficial do material de suporte apresentou uma pequena redução após adição dos diferentes teores de prata. A área superficial do suporte mostrou-se capaz de permitir a incorporação das diversas quantidades de prata na sua superfície mantendo o diâmetro das partículas depositadas entre 3,6 e 7,1 nm com percentagens de dispersão entre 23 e $16 \%$. As percentagem de prata obtidas na detecção semi-quantitativa EDS confirmou a correta impregnação das diversas quantidades de prata no material de suporte.

Tabela 1 - Propriedades físicas e químicas do suporte $\gamma-\mathrm{Al}_{2} \mathrm{O}_{3}$ e dos catalisadores $\mathrm{Ag} / \mathrm{Al}_{2} \mathrm{O}_{3}$.

\begin{tabular}{ccccc}
\hline Catalisador & $\begin{array}{c}\text { Teor de prata } \\
\text { SEM/EDS }(\% \\
\text { elementar })\end{array}$ & $\begin{array}{c}\text { Área superficial } \\
\text { BET }\left(\mathrm{m}^{2} \mathrm{~g}^{-1}\right)\end{array}$ & $\begin{array}{c}\text { Diâmetro de partícula } \\
\text { metálica }(\mathrm{nm})\end{array}$ & $\begin{array}{c}\text { Dispersão } \\
(\%)\end{array}$ \\
\hline$\gamma-\mathrm{Al}_{2} \mathrm{O}_{3}$ & - & 176 & - & - \\
$0,5 \% \mathrm{Ag} / \mathrm{Al}_{2} \mathrm{O}_{3}$ & 0,73 & 174 & 3,6 & 23 \\
$1 \% \mathrm{Ag} / \mathrm{Al}_{2} \mathrm{O}_{3}$ & 1,23 & 175 & 4,4 & 22 \\
$2 \% \mathrm{Ag} / \mathrm{Al}_{2} \mathrm{O}_{3}$ & 2,23 & 171 & 5,6 & 20 \\
$3 \% \mathrm{Ag} / \mathrm{Al}_{2} \mathrm{O}_{3}$ & 3,15 & 172 & 6,0 & 19 \\
$5 \% \mathrm{Ag} / \mathrm{Al}_{2} \mathrm{O}_{3}$ & 5,53 & 166 & 7,1 & 16 \\
\hline
\end{tabular}

\subsection{Atividade catalítica dos catalisadores $\mathrm{Ag} / \mathrm{Al}_{2} \mathrm{O}_{3}$ na reação de oxidação parcial do etanol}

Conforme mostrado na Figura 4(a), nos testes catalíticos desenvolvidos a conversão de etanol apresentou um grande aumento causado pelo incremento tanto no teor de prata nos catalisadores como na temperatura de reação. Conforme apresentado na figura 4(b), a conversão do oxigênio utilizando o catalisador $0,5 \% \mathrm{Ag} / \mathrm{Al}_{2} \mathrm{O}_{3}$ teve um aumentou moderado com o aumento da temperatura de reação, enquanto para os catalisadores com teor de prata acima de $1 \% \mathrm{~m} / \mathrm{m}$ mostrou um maior incremento a partir dos $190^{\circ} \mathrm{C}$. O oxigênio alimentado foi completamente consumido a $220^{\circ} \mathrm{C}$ utilizando o catalisador $5 \% \mathrm{Ag} / \mathrm{Al}_{2} \mathrm{O}_{3}$ devido à maior quantidade de partículas de prata disponíveis para sua adsorção. 

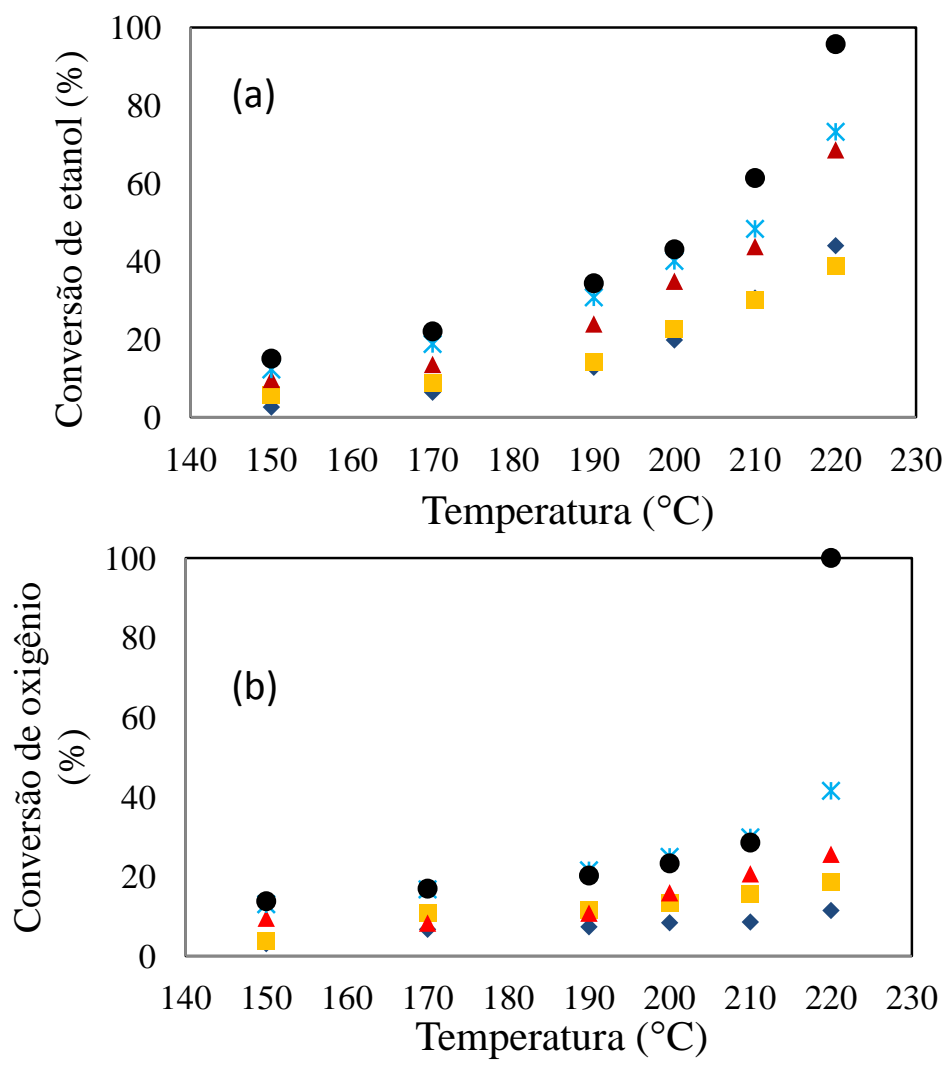

Figura 4 - Conversão do etanol (a) e do oxigênio (b) em função do teor de prata e da temperatura de reação utilizando os catalisadores $0,5 \% \mathrm{Ag} / \mathrm{Al}_{2} \mathrm{O}_{3}(\bullet), 1 \% \mathrm{Ag} / \mathrm{Al}_{2} \mathrm{O}_{3}(\varpi)$,

$$
2 \% \mathrm{Ag} / \mathrm{Al}_{2} \mathrm{O}_{3}(\Delta), 3 \% \mathrm{Ag} / \mathrm{Al}_{2} \mathrm{O}_{3}(*) \text { e } 5 \% \mathrm{Ag} / \mathrm{Al}_{2} \mathrm{O}_{3}(\bullet) \text {. }
$$

$\mathrm{O}$ principal produto da oxidação parcial do etanol nos catalisadores $\mathrm{Ag} / \mathrm{Al}_{2} \mathrm{O}_{3}$ foi o acetaldeído, sendo produzidos também o dietil éter, dióxido de carbono, etileno, metanol, ácido acético e água. Outros produtos convencionais da oxidação do etanol tais como o monóxido de carbono e o hidrogênio não foram produzidos nas condições de reação utilizadas.

Conforme mostrado na Figura 5, a seletividade aos produtos durante a oxidação do etanol nos catalisadores $\mathrm{Ag} / \mathrm{Al}_{2} \mathrm{O}_{3}$ foi altamente influenciada pelo teor de prata e pela temperatura. Para temperaturas de reação entre 150 e $200^{\circ} \mathrm{C}$ a seletividade a acetaldeído apresentou valores acima dos $95 \%$ a partir do catalisador $2 \% \mathrm{Ag} / \mathrm{Al}_{2} \mathrm{O}_{3}$, e manteve estes valores inclusive a maiores conversões de etanol utilizando os catalisadores $3 \% \mathrm{Ag} / \mathrm{Al}_{2} \mathrm{O}_{3} \mathrm{e}$ $5 \% \mathrm{Ag} / \mathrm{Al}_{2} \mathrm{O}_{3}$. No entanto, para toda a faixa de temperatura, o dietil éter apresentou seletividades entre 52 e $72 \%$ utilizando o catalisador $0,5 \% \mathrm{Ag} / \mathrm{Al}_{2} \mathrm{O}_{3}$ e entre 5 e $17 \%$ utilizando o catalisador $1 \% \mathrm{Ag} / \mathrm{Al}_{2} \mathrm{O}_{3}$. A seletividade a dietil éter nestes catalisadores é atribuída ao baixo teor de prata e ao efeito catalítico da alumina. Observou-se também a formação de $\mathrm{CO}_{2}$ a partir dos $200^{\circ} \mathrm{C}$ utilizando o catalisador $5 \% \mathrm{Ag} / \mathrm{Al}_{2} \mathrm{O}_{3}, 210^{\circ} \mathrm{C}$ utilizando os catalisadores $3 \% \mathrm{Ag} / \mathrm{Al}_{2} \mathrm{O}_{3}$ e $2 \% \mathrm{Ag} / \mathrm{Al}_{2} \mathrm{O}_{3}$, e $220^{\circ} \mathrm{C}$ utilizando o catalisador $1 \% \mathrm{Ag} / \mathrm{Al}_{2} \mathrm{O}_{3}$. Este resultado indica que para maiores teores de prata no catalisador, menores temperaturas de reação são necessárias para o desenvolvimento da oxidação total do etanol. Cabe destacar que, neste trabalho a formação do $\mathrm{CO}_{2}$ também foi favorecida pela baixa razão molar 
Etanol $/ \mathrm{O}_{2}$ utilizada nos testes catalíticos. Uma baixa seletividade a etileno $(\approx 1 \%)$ foi observada para os catalisadores $0,5 \% \mathrm{Ag} / \mathrm{Al}_{2} \mathrm{O}_{3}$ e $1 \% \mathrm{Ag} / \mathrm{Al}_{2} \mathrm{O}_{3}$ acima dos $210^{\circ} \mathrm{C}$, como resultado da mudança de seletividade de dietil éter a etileno durante a reação de desidratação de etanol catalisada em sítios ácidos [Varisly et al., 2007]. Por último, acima dos $210^{\circ} \mathrm{C}$ também foram produzidos metanol e ácido acético utilizando os catalisadores com teor de prata de 2 a $5 \% \mathrm{~m} / \mathrm{m}$.
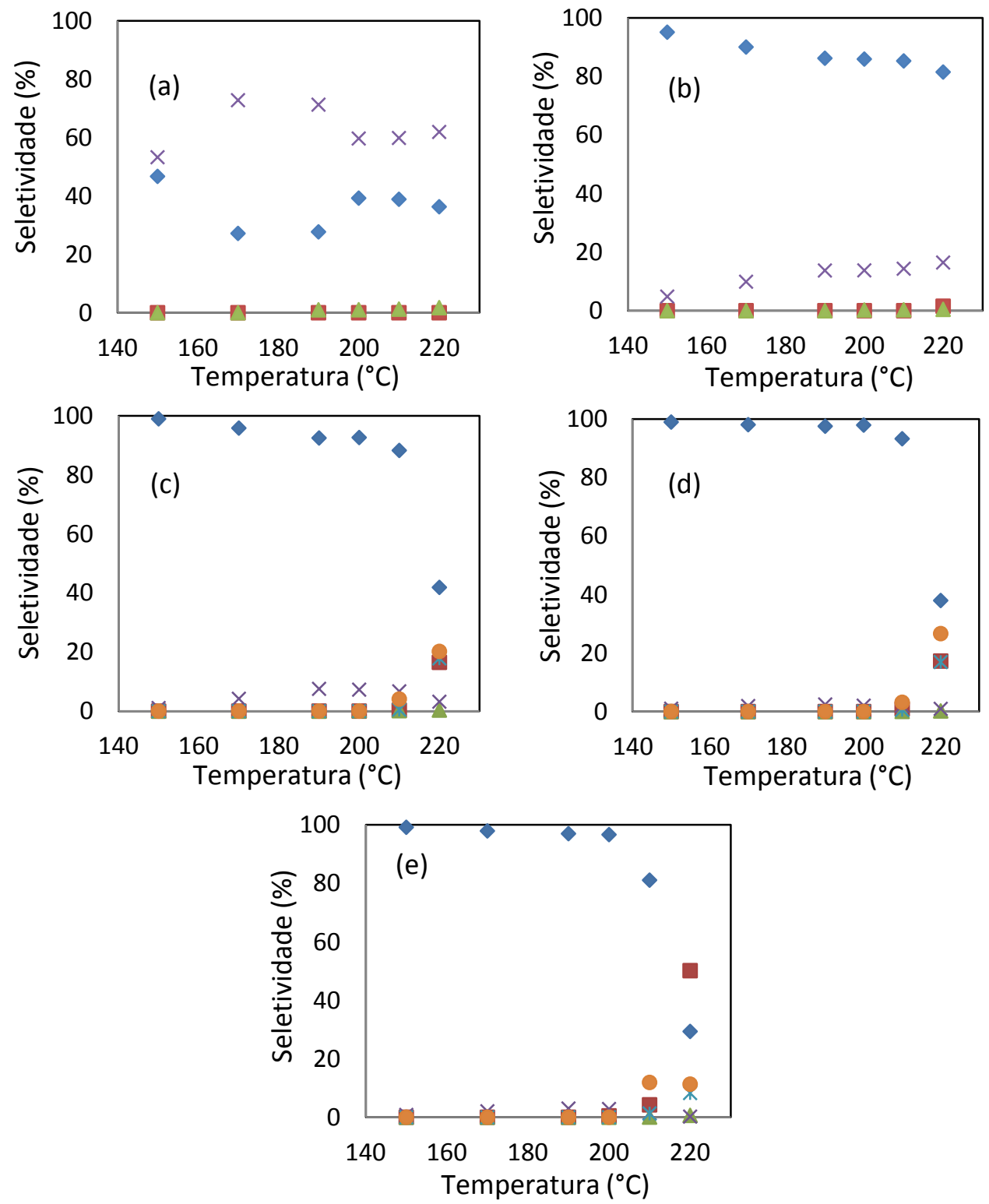

Figura 5 - Seletividade a acetaldeído $(\bullet)$, dietil éter $(\times)$, dióxido de carbono $(\bullet)$, etileno $(\Delta)$, metanol ( $*$ ) e ácido acético $(\bullet)$ em função do teor de prata e da temperatura utilizando os catalisadores $0,5 \% \mathrm{Ag} / \mathrm{Al}_{2} \mathrm{O}_{3}(\mathrm{a}), 1 \% \mathrm{Ag} / \mathrm{Al}_{2} \mathrm{O}_{3}(\mathrm{~b}), 2 \% \mathrm{Ag} / \mathrm{Al}_{2} \mathrm{O}_{3}(\mathrm{c}), 3 \% \mathrm{Ag} / \mathrm{Al}_{2} \mathrm{O}_{3}$ (d) e $5 \% \mathrm{Ag} / \mathrm{Al}_{2} \mathrm{O}_{3}(\mathrm{e})$. 


\section{CONCLUSÃO}

Os testes catalíticos desenvolvidos neste trabalho mostraram que a reação de oxidação parcial do etanol é altamente seletiva a acetaldeído em catalisadores $\mathrm{Ag} / \mathrm{Al}_{2} \mathrm{O}_{3}$ com teor de prata igual ou superior a $2 \% \mathrm{~m} / \mathrm{m}$, e a temperaturas de reação entre 150 e $200^{\circ} \mathrm{C}$. Maiores temperaturas de reação conduzem à formação de outros produtos como o $\mathrm{CO}_{2}$, metanol e ácido acético devido à influência do suporte e às altas conversões de etanol e oxigênio. Os catalisadores com teores de prata menores a $2 \% \mathrm{~m} / \mathrm{m}$ favorecem uma alta seletividade a dietil éter produzido pela reação de desidratação do etanol catalisada nos sítios ácidos da alumina. Finalmente, a informação reportada neste trabalho contribui para o estudo das reações de oxidação seletiva de etanol em catalisadores de prata suportada.

\section{AGRADECIMENTOS}

Os autores agradecem à Coordenação de Aperfeiçoamento de Pessoal de Nível Superior (CAPES) pelo apoio financeiro.

\section{REFERÊNCIAS BIBLIOGRÁFICAS}

ABAD, A.; CONCEPCIÓN, P.; CORMA, A.; GARCIA, H. A Collaborative Effect Between Gold and a Support Induces the Selective Oxidation of Alcohols Angew. Chem. Int. v. 44, p. 4066-4069, 2005.

CHIMENTÃO, R. J; HERRERA. J. E; KWAK, J. H; MEDINA, F; WANG, Y; PEDEN, C. H. F. Oxidation of ethanol to acetaldehyde over Na-promoted vanadium oxide catalysts. Applied Catalysis A: General, v. 332, p. 263-272, 2007.

DE LIMA, A. F. F; COLMAN, R. C; ZOTIN, F. M. Z; APPEL, L. G. Acetaldehyde behavior over platinum based catalyst in hydrogen stream generated by ethanol reforming.

International journal of hydrogen energy, v. 35, p. 13200-13205, 2010.

GONG, J.; MULLIN CB. Selective oxidation of ethanol to acetaldehyde on gold. J Am Chem Soc, v. 130, n. 49, p.16458-9, 2008.

HEBBEN, N.; DIEHM, C.; DEUTSCHMANN, O. Catalytic partial oxidation of ethanol on alumina-supported rhodium catalysts: An experimental study. Applied Catalysis A: General, v. 388 , p. $225-231,2010$.

HO-JEONG, C; TAE-WAN, K; YOUNG-KYUN, M; HAN-KYU, K; KWANG-EUN, J; CHUL-UNG, Kim; SOON-YONG, J. Butadiene production from bioethanol and acetaldehyde over tantalum oxide-supported ordered mesoporous silica catalysts. Applied Catalysis B: Environmental, v. 150-151, p. 596-604, 2014.

LIN, R; LUO, M. F; XIN, Q; SUN, G. Q. The mechanism studies of ethanol oxidation on PdO catalysts by TPSR techniques. Catalysis Letters, v.. 93, n. 3-4, 2004.

LIU, X.; MADIX, R. J.; FRIEND, C. M. Unraveling molecular transformations on surfaces: a critical comparison of oxidation reactions on coinage metals. Chem. Soc. Rev., v. 37, p. 22432261, 2008.

MADHAVARAM, H; IDRISS, H. Acetaldehyde reactions over the uranium oxide system. Journal of Catalysis, v. 224, p. 358-369, 2004. 
MURCIA, J. J; HIDALGO, M.C.; NAVÍO, J.A.; VAIANO, V; CIAMBELLI, P; SANNINO, D. Ethanol partial photoxidation on $\mathrm{Pt} / \mathrm{TiO}_{2}$ catalysts as green route for acetaldehyde synthesis. Catalysis Today, v. 196, p. 101- 109, 2012.

QIAN, M.; LIAUW, M. A.; EMIG, G. Formaldehyde synthesis from methanol over silver catalysts. Applied Catalysis A: General, v. 238, p. 211-222, 2003.

RESTA, A.; GUSTAFSON, J.; WESTERSTRÖN, R.; MIKKELSEN, A.; LUNDGREN, E.; ANDERSEN, J. N.; YANG, M. M. Y.; MA, X. F.; BAO, X. F.; LI, W. X. Step Enhanced Dehydrogenation of Ethanol on Rh. Surface Science, v. 602, p. 3057-3063, 2008.

TEMBE, S. M.; PATRICK, G.; SCURRELL, M. S. Acetic acid production by selective oxidation of ethanol using Au catalysts supported on various metal oxide. Gold Bulletin, v. 42 n. 4, 2009.

VARISLI, D; DOGU, T; DOGU, G. Ethylene and diethyl-ether production by dehydration reaction of ethanol over different heteropolyacid catalysts. Chemical Engineering Science, v. 62, p. $5349-5352,2007$.

VAN SANTEN, R. A.; DE GROOT, C. P. M. The Mechanism of Ethylene Epoxidation. Journal of Catalysis, v. 98, p. 530-539, 1986.

VODYANKINA, O. V.; KURINA, L. N.; BORONIN, A. I.; SALANOV A. N. Glyoxal Synthesis by Vapour-Phase Ethylene Glycol Oxidation on a Silver and Copper Catalysts. Studies in Surface Science and Catalysis, v. 130, p. 1775-1780, 2000.

YONEDA, N; KUSANO, S; YASUI, M; PUJADO, P, WILCHER, S. Recent advances in processes and catalysts for the production of acetic acid. Applied Catalysis A: General, v. 221, p. 253-265, 2001. 